\title{
Production Strategy for Manufacturing Large-Scale AISi10Mg Components by Laser Powder Bed Fusion
}

\author{
FEDERICO BOSIO, ${ }^{1,2,3}$ HAOPENG SHEN, ${ }^{1,2}$ YANG LIU, ${ }^{1,2}$ \\ MARIANGELA LOMBARDI ${ }^{3}$ PAUL ROMETSCH, ${ }^{1,2,4}$ XINHUA WU, ${ }^{1,2}$ \\ YUMAN ZHU (iD, ${ }^{1,2,5}$ and AIJUN HUANG ${ }^{1,2,6}$ \\ 1.-Monash Centre for Additive Manufacturing, Notting Hill, VIC 3168, Australia. \\ 2.-Department of Materials Science and Engineering, Monash \\ University, Clayton, VIC 3800, Australia. 3.-Department of Applied Science and \\ Technology, Politecnico di Torino, Corso Duca degli Abruzzi 24, 10129 Turin, Italy. 4.-Present \\ address: Arvida Research and Development Centre, Rio Tinto, Jonquiere, QC G7S 4K8, Canada. \\ 5.—e-mail: yuman.zhu@monash.edu.6.—e-mail: aijun.huang@monash.edu
}

The long production time required for large-scale parts fabricated by laser powder bed fusion (LPBF) tends to induce cracks, distortions, and overheating problems. In this work, to address these challenges, we explored and established a suitable strategy for producing large AlSi10Mg components. The platform temperatures to prevent cracks and distortions were firstly determined. Then, the in situ aging behavior was investigated for samples under various platform temperatures and holding times. Our results revealed that platform temperatures of $150^{\circ} \mathrm{C}$ and $200^{\circ} \mathrm{C}$ can effectively prevent cracks and minimize distortions. Besides, using $150^{\circ} \mathrm{C}$, samples can reach peak hardness with a holding time less than $13 \mathrm{~h}$. In comparison, those samples produced with a holding time longer than $13 \mathrm{~h}$ at $150^{\circ} \mathrm{C}$ and $200^{\circ} \mathrm{C}$ show obvious overaging responses and thus lower hardness. However, such a hardness impoverishment can be recovered by using a T6 post-process heat-treatment.

\section{INTRODUCTION}

Laser powder bed fusion (LPBF), as one of the typical additive manufacturing (AM) technologies, is a profitable alternative to conventional casting for the production of complex-shaped metal parts. ${ }^{1,2}$ However, former LPBF printing machines with limited building chamber dimensions only allow the fabrication of small-sized components. Therefore, LPBF systems with higher building volumes have been introduced to the market for large-scale manufacturing. Nevertheless, producing massive components made of aluminum alloys by LPBF still involves essential challenges to tackle. One issue is represented by the internal residual stresses arising from the rapid solidification. Such stresses will generate severe distortion and cracks, and will eventually lead to job failure. ${ }^{3}$ Since the LPBF

Federico Bosio and Haopeng Shen contribute equally to the work.

(Received April 3, 2020; accepted December 2, 2020;

published online January 4, 2021) process is relatively slow compared with foundry techniques, building large parts by LPBF requires rather a long printing time. Consequently, those defects must be prevented to save time and powder. On this basis, heating the building platform throughout printing has been suggested to be effective in alleviating residual stresses and deformation of built parts. ${ }^{4}$ Also, the heated building plate can reduce the solidification shrinkage of components due to the reduced thermal gradient.,

Over the last decade, the Al-Si based alloys, i.e., $4 \mathrm{xxx}$ aluminum alloys, have been widely processed by LPBF because their final products potentially meet the industrial requirements in terms of being lightweight, having shape freedom, and good thermal conductivity. ${ }^{6-10}$ Since these alloys can be agehardened, ${ }^{11}$ the platform heating strategy can also induce the age-hardening effects to further improve the mechanical properties of the products, besides alleviating distortions and cracks. ${ }^{12-14}$ Specifically, Aversa et al. investigated the effect of various building platform temperatures on the 
strength and microstructure of an LPBF-produced A357 alloy. ${ }^{12}$ Their results revealed the appearance of $\mathrm{Mg}_{2} \mathrm{Si}$ precipitates at different building platform temperatures due to the in situ aging induced by the heated platform during LPBF. Later, similar precipitates were confirmed by using differential scanning calorimetry (DSC) to examine the thermal ramp of an AlSi $10 \mathrm{Mg}$ alloy processed by selective laser melting (SLM) with a platform heated to $160^{\circ} \mathrm{C} .{ }^{13}$ However, the hardness profile of a cylindrical bar of $100 \mathrm{~mm}$ in length did not show any significant age-hardening response along the building direction. ${ }^{13}$ Recently, the precipitation of Si particles at a nano-scale has been reported in the as-built SLM-produced A357 alloy with a platform temperature of $80^{\circ} \mathrm{C} .{ }^{14}$ Also, satisfactory tensile properties were reported, although the alloy exhibited a relatively low hardness in both as-built and directly aged conditions. The reason was mainly ascribed to the loss of solid-solution strengthening caused by the formation of nano-precipitates. Buchbinder et al. performed a systematic investigation on the effect of varied platform heating temperatures on distortions of AlSi10Mg components processed by SLM. ${ }^{15}$ It was concluded that a platform temperature of $250^{\circ} \mathrm{C}$ was appropriate to completely prevent distortions, although a low hardness value $(\sim 80 \mathrm{HV})$ was associated with the material. This value, however, is still higher than the hardness standard DIN EN 1706 for die-cast counterparts. Nonetheless, for the production of large-scale components, this hardness impoverishment could be further encouraged by the long holding time above the heated platform and, therefore, more research is needed to solve this issue.

In this work, a production strategy for manufacturing large parts made of AlSi10Mg by LPBF is proposed. Two main vital design aspects are concurrently addressed for the first time. The first is the prevention of cracks and support distortions, which may lead to job failure. By using the platform heating strategy, we first determined the platform temperatures that can alleviate macroresidual stresses by using an optimized processing setup. Then, the second crucial aspect addressed in this work is the age-hardening effect induced by the heated platform. In this aspect, by producing the same samples with different printing times on a platform heated at $150^{\circ} \mathrm{C}$, we clearly show that the in situ aging behavior not only depends on the holding time on the heated platform but also the position along the building direction. Also, the printing time limit to avoid in situ over-aging at $150^{\circ} \mathrm{C}$ was determined. Finally, for the production of large-scale parts with a platform temperature of $200^{\circ} \mathrm{C}$, it was demonstrated that over-aging occurs during printing, and a post-process heat treatment can effectively increase the hardness.

\section{MATERIALS AND METHODS}

\section{Powder and LPBF Process}

Pre-alloyed gas-atomized powder of AlSi10Mg (TLS Technik GmbH \& Co., Bitterfeld) was used in this work. The chemical composition of the powder can be found in supplementary Table S-I. Direct current emission spectroscopy was used to detect metal elements (ASTM E 1097-12), while oxygen and nitrogen were analyzed via inert gas fusion (ASTM E 1019-11). The field-emission gun scanning electron microscope (SEM) JEOL JSM$7001 \mathrm{~F}$ was used to evaluate particle shape and morphology. The size distribution was determined using laser diffraction analysis (Malvern Mastersizer 2000). Most particles of the gas-atomized powder have a spherical shape (Fig. 1a), and a mean size of $34 \mu \mathrm{m}$ (Fig. 1b).

The optimized processing parameters in an EOS M290 system (EOS Gmbh) have been adopted in this work to manufacture the AlSi10Mg specimens, see supplementary Table S-II. A Yb-fiber laser with a wavelength of $1060-1100 \mathrm{~nm}$ and a nominal power of $370 \mathrm{~W}$ were used to melt a thin powder layer locally. The scanning speed of the laser was $1300 \mathrm{~mm} / \mathrm{s}$. Also, argon gas was applied in the building chamber to reduce the oxygen content below $0.1 \%$. In addition, a $67^{\circ}$ rotated scanning strategy was adopted to achieve isotropic properties in the plane parallel to the building platform. ${ }^{16} \mathrm{~A}$ heated building platform was utilized to investigate its effects on the cracks, distortions, and the in situ aging response. It is worth noting that this strategy is different from platform preheating for LPBF. ${ }^{17,18}$ We kept the platform at a constant temperature $(T)$ throughout the building process. The specific $T$ levels used in this study were selected based on previous work, see supplementary Table S-II. ${ }^{7,12-14}$

\section{Cracks and Distortions Assessment}

The production of large parts can prematurely fail during LPBF when the internal residual stresses lead to severe distortions, cracks, delamination, and buckling. In this work, the platform heating method was applied to alleviate these phenomena. To study the effect of various building platform temperatures on the formation of cracks and distortions, the 'twin cantilever' method proposed by Buchbinder et al. ${ }^{15}$ was adopted for this work. Cantilever samples with twin arms of $50 \mathrm{~mm}$ in length and $3 \mathrm{~mm}$ in thickness (Fig. 2) were built at $T$ of $45^{\circ} \mathrm{C}$ room temperature $(R T), 100^{\circ} \mathrm{C}, 150^{\circ} \mathrm{C}$, and $200^{\circ} \mathrm{C}$. Surface profiles were recorded using a Mitutoyo CRYSTAApex S700 CNC coordinate measuring machine with a position accuracy of $1.7 \mu \mathrm{m}$ to obtain the reference baseline. Then, support fins of the righthand arm were cut using electric discharging machining in the proximity of the building plate. All cantilever profiles were measured again to evaluate the extent of arm deflection after removal 

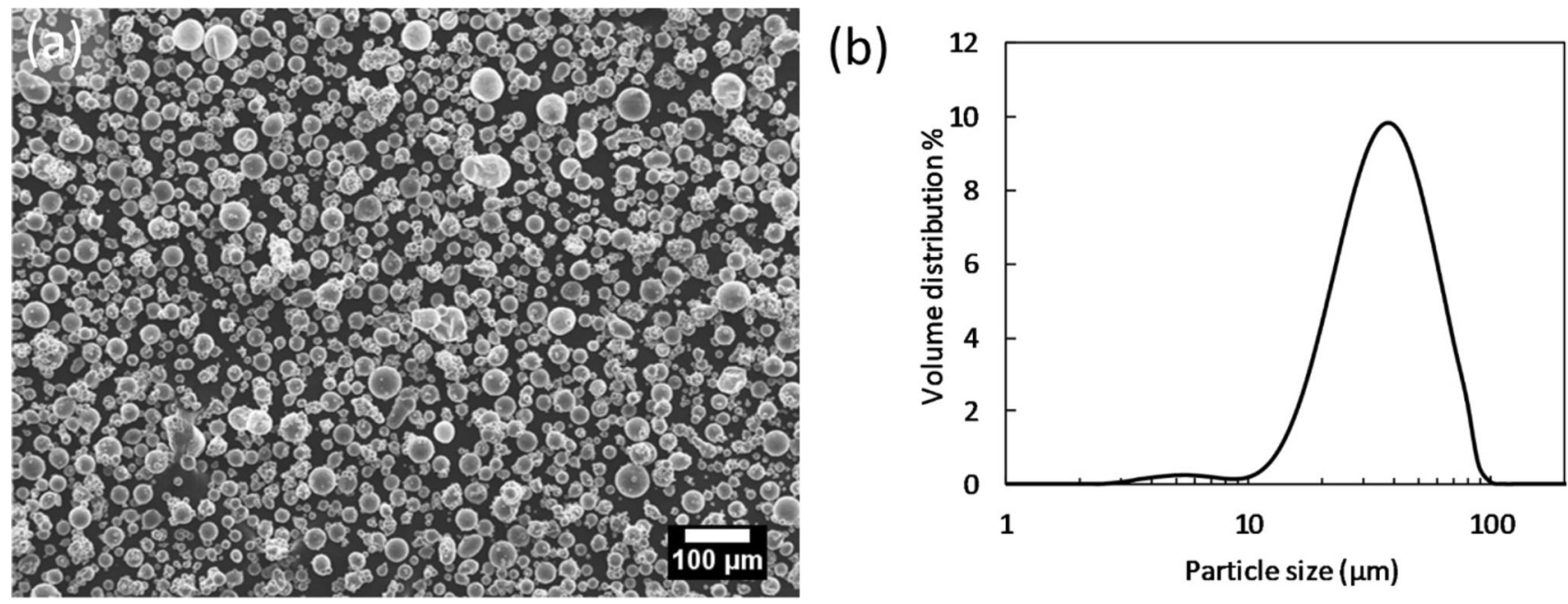

Fig. 1. (a) AISi10Mg powder observed by SEM, and (b) powder size distribution.

from the building plate. Profile measurements were carried out along the middle axis of the cantilever with a probe displacement of $1 \mathrm{~mm}$. Five cantilever profiles for each condition were averaged to determine the overall deflection curve. On this basis, the appropriate platform heating temperatures were selected for the further in situ aging study.

\section{In-Situ Aging Assessment}

Building large parts by LPBF may require a long printing time (up to 1 week occasionally). The LPBF printing time, $t$, relies on the process parameters and volume number of parts to be printed. For this reason, two AlSi10Mg jobs with a low and high packing density of samples, corresponding to a LPBF printing time $t$ of $13.4 \mathrm{~h}$ and $53 \mathrm{~h}$ respectively, were designed (Fig. 3). Parallelepiped samples with dimensions of $11 \times 85 \times 35 \mathrm{~mm}^{3}$ were built by using a platform heating at $150^{\circ} \mathrm{C}$. The Vickers micro-hardness (HV0.5) was evaluated along the building direction of as-built samples using the Duramin A330 hardness tester with a load of $0.5 \mathrm{~kg}$ and a dwell time of $10 \mathrm{~s}$. Six samples for each condition were investigated to obtain the overall HV behavior. The hardness measurement was performed at specific height levels along the $z$ axis. A total of 30 measures was made for each height level. The LPBF holding time of each height level can be determined by

$$
\tau_{i}=\frac{\left(h-h_{i \_\mathrm{HV}}\right)}{h} \cdot t
$$

where $\tau_{i}$ is the LPBF holding time corresponding to the specific hardness tested level $h_{i \mathrm{HV}}, h$ is the total sample height ( $35 \mathrm{~mm})$, and $t$ is the LPBF printing time.

Samples for SEM investigation were ground and polished, and then etched in Kroll's reagent for $15 \mathrm{~s}$. SEM images and energy-dispersive X-ray spectroscopy (EDS) maps were obtained using the JEOL JSM-7001F microscope.

\section{Post-Process Heat Treatments}

Cubes with dimensions of $10 \times 10 \times 10 \mathrm{~mm}^{3}$ were produced using a platform heating temperature of $200^{\circ} \mathrm{C}$ and a printing time of roughly $10 \mathrm{~h}$. To mimic the heated platform effect for large parts, we conducted a long-term isothermal heat treatment at $200^{\circ} \mathrm{C}$ for up to $100 \mathrm{~h}$ on the as-built samples. The temperature inside the furnace chamber was set at the same $T$ used throughout LPBF and monitored by a thermocouple $\left(\Delta T \pm 1^{\circ} \mathrm{C}\right)$. Later, all samples were heat-treated by a T6-like solution $\left(520^{\circ} \mathrm{C} / 1 \mathrm{~h}+\right.$ water quenching $\left.+160^{\circ} \mathrm{C} / 6 \mathrm{~h}\right)$ to evaluate the effect of such heat treatment on the hardness and microstructure. The gap time between solid solution and artificial aging was controlled and kept below $30 \mathrm{~min}$. For each sample, five Vickers hardness (HV $0.5 \mathrm{~kg} / 10 \mathrm{~s}$ ) measurements along the building direction were performed according to ASTM E92-17.

\section{RESULTS}

By using the platform heating strategy, the platform temperatures able to prevent cracks were first examined to uncover a safe route for the production of large-scale components (Fig. 4a and b). The micrographs in Fig. 4a depict cantilever parts built at different platform heating temperatures $T$ ahead of supports removal. A qualitative analysis of Fig. 4 a reveals that various defects, such as cracks and support distortions, appear at $45^{\circ} \mathrm{C}$ and $100^{\circ} \mathrm{C}$. The origin of these defects is associated with the first consolidated layers between the support structure and horizontal arms of twin cantilever samples. These distortions and cracks reduce significantly on the cantilevers built at $150^{\circ} \mathrm{C}$ and $200^{\circ} \mathrm{C}$. The number of cantilever deflections as a function of the platform temperatures is 


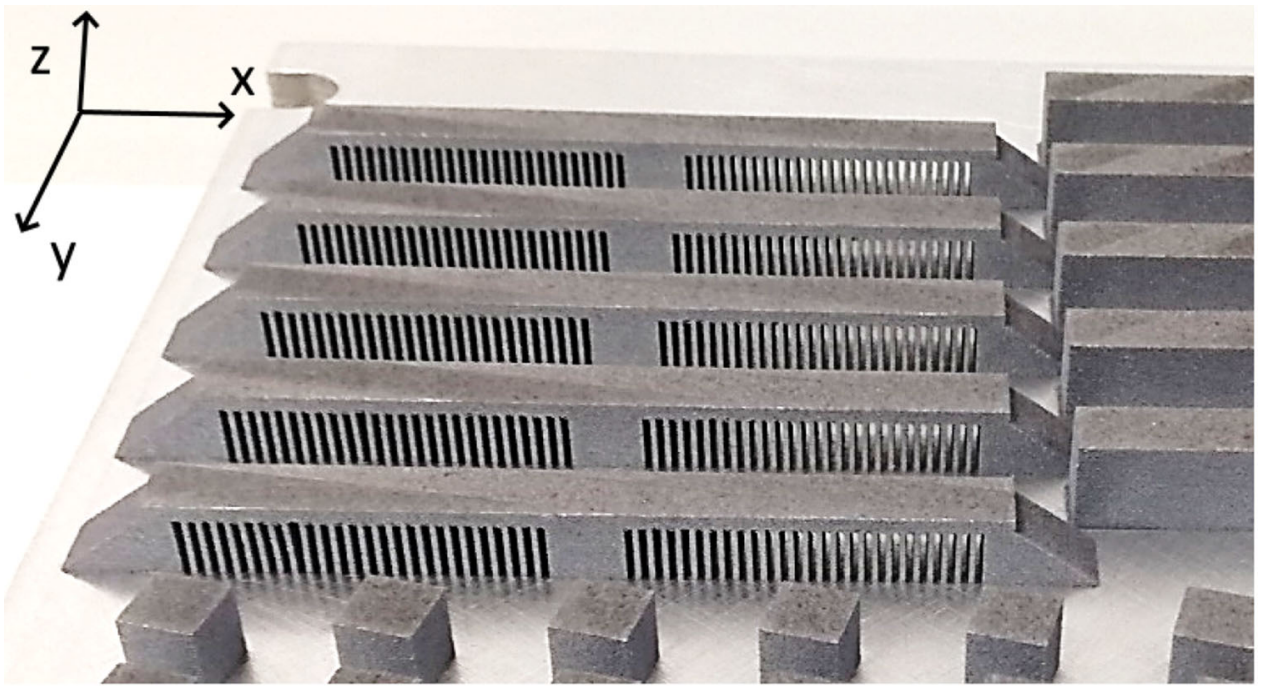

Fig. 2. Twin cantilever samples of AISi10Mg alloy produced by LPBF. The $z$-direction represents the building direction.

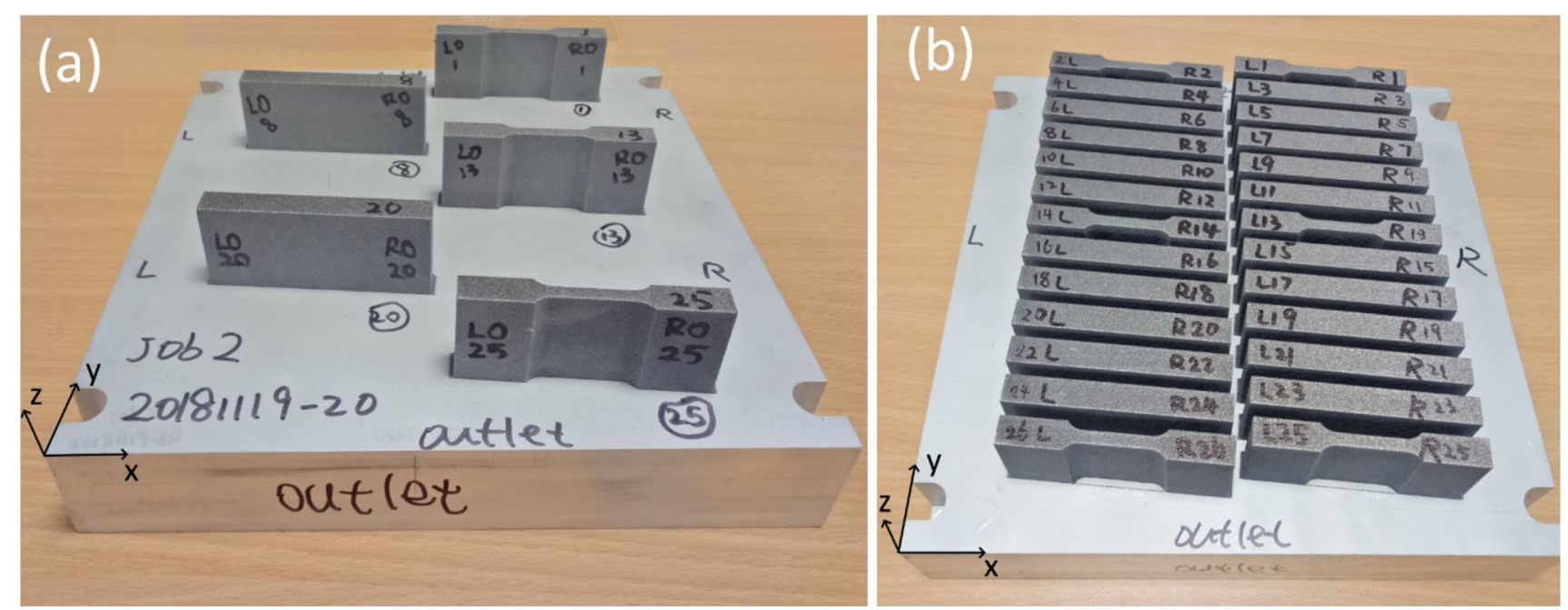

Fig. 3. (a) Low and (b) high packing density jobs of AISi10Mg samples, corresponding to a total LPBF printing time of $13.4 \mathrm{~h}$ and $53 \mathrm{~h}$, respectively. The $z$-direction represents the building direction.

shown in Fig. 4b. Given that most of the residual stresses generated in LPBF are released after support removal, they will give rise to the bent deflections associated with the samples. The maximum deflection $\Delta Z$ is recorded at the connection edge between the substrate and the cantilever built at $45^{\circ} \mathrm{C}$. At higher platform temperatures, the $\Delta Z$ reduction measured at the cantilever edge was $34 \%$ and $54 \%$ for $100^{\circ} \mathrm{C}$ and $150^{\circ} \mathrm{C}$, respectively. There was no obvious deflection detected at a platform temperature of $200^{\circ} \mathrm{C}$.

Based on the results in Fig. $4 \mathrm{a}$ and b, both platform temperatures at $150^{\circ} \mathrm{C}$ and $200^{\circ} \mathrm{C}$ can effectively prevent crack formation and minimize distortions in cantilever parts, which is a vital requirement for a successful job when large LPBF parts are produced. Therefore, these two temperatures were selected for the subsequent in situ aging studies. It should be noted that the former melted $i$-layer close to the heated substrate experiences a longer holding time than the later consolidated one $(i+1$ layer $)$ during the LPBF process. Hence, the hardness associated with different sample height is likewise different. Figure 5 provides the hardness values along the $z$-direction of the samples of $35 \mathrm{~mm}$ in height that were built at a platform temperature of $150^{\circ} \mathrm{C}$ for $13.4 \mathrm{~h}$ and $53 \mathrm{~h}$. Considering the hardness profile after a printing time of $13.4 \mathrm{~h}$, there was a significant hardness increment when the building time reached $2.5 \mathrm{~h}$, which corresponds with the top part of the sample (i.e., $h$ is between 23.7 and $35 \mathrm{~mm}$ ). Then the hardness reaches a plateau value of $\sim 137 \mathrm{HV}$ between $2.5 \mathrm{~h}$ and $12.4 \mathrm{~h}$. However, for the 

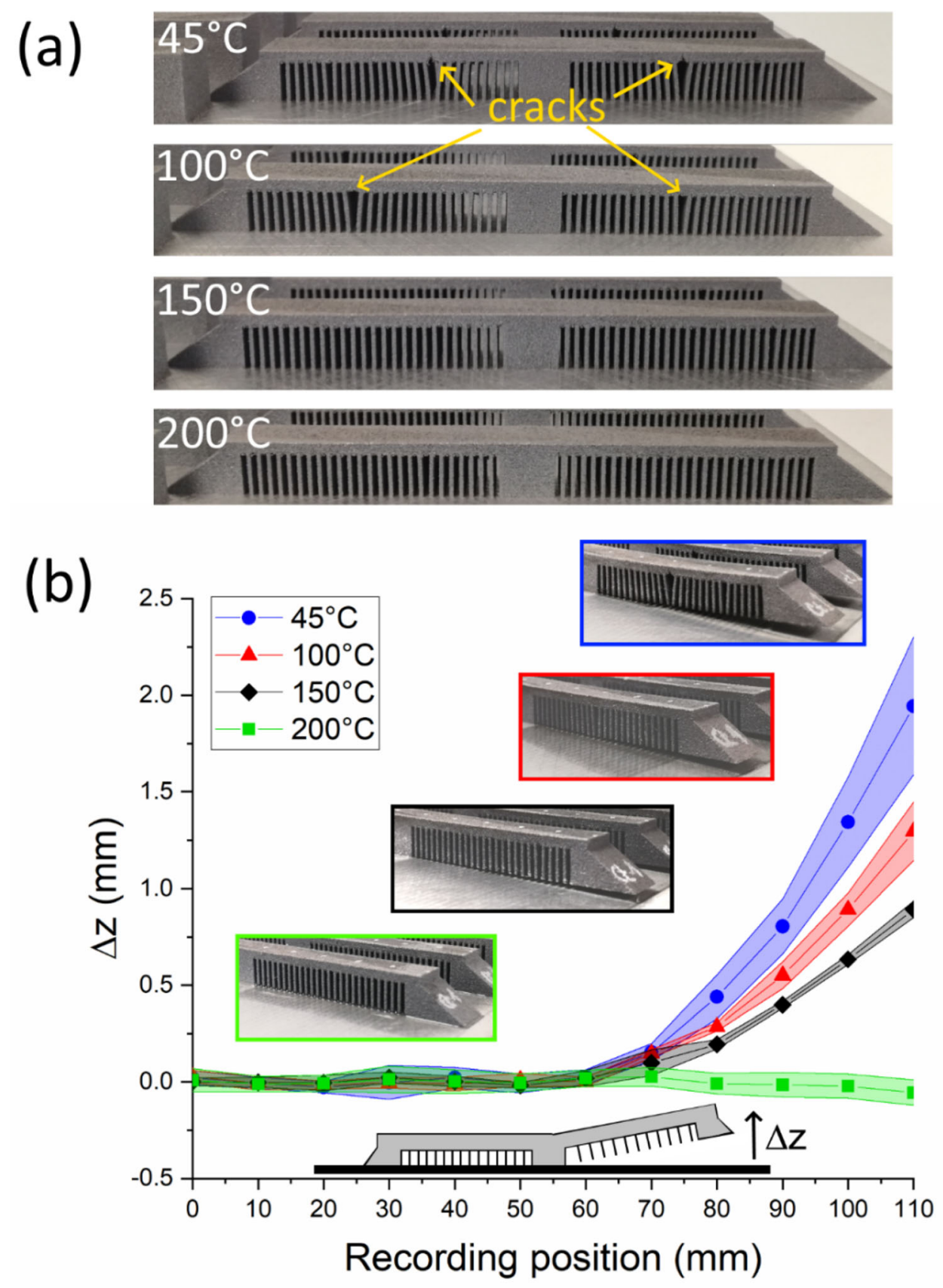

Fig. 4. (a) Macroscopic defects identified on twin cantilever samples at different platform heating temperatures; (b) deflection ( $\Delta Z$ ) of twin cantilever after removing from the supports at different platform heating temperatures. Colored bands represent the measured standard deviations along the length of one side of the cantilever (from center to end). Inset pictures show the distortions at different plate temperatures.

hardness profile after $53 \mathrm{~h}$ of printing time, a value drop in the curve can be identified. This suggests the occurrence of over-aging in this part of the sample. Specifically, a peak-age of around $138.6 \mathrm{HV}$ is firstly encountered at $\tau$ of $13.4 \mathrm{~h}$. Then, by further increasing $\tau$, hardness is greatly reduced throughout the volume of material that experiences longer holding time, i.e., $49.2 \mathrm{~h}$, on the heated platform. According to the results shown in Fig. 5, the AlSi10Mg building part has reached the peak-aged condition in most regions (up to $h=27 \mathrm{~mm}$ ) using a printing time of $13.4 \mathrm{~h}$, whereas it is very probable that over-aging occurred when $53 \mathrm{~h}$ of LPBF printing time elapses.

Microstructural examination for selected positions of samples along the building direction further confirms the occurrence of in situ aging, as shown in Fig. 6. Based on these images, the overall response of AlSi10Mg alloy to the fast cooling rate of the LPBF process $\left(1 \times 10^{5} \mathrm{~K} / \mathrm{s}\right)^{19}$ results in a very fine microstructure with submicron-sized primary $\alpha$-Al cells (gray color) surrounded by fibrous eutectic 
boundaries (bright and light gray color). These eutectic boundaries are highly abundant in $\mathrm{Si}$ (see supplementary Fig. S-1), which is consistent with previous studies on SLM-produced AlSi10Mg. ${ }^{20-22}$ Since the investigated alloy was known to be sensitive to precipitation hardening, the presence of various intracolumnar super-fine particles was remarkably higher when the samples experience longer holding times (Fig. 6e and f). There was no significant variation of $\alpha$-Al column size in terms of dendrite width $(\lambda=0.39-0.44 \mu \mathrm{m})$. When the same sample height but different LPBF printing times were compared, a similar microstructural difference was found, i.e., the higher number density of precipitates in Fig. 6d-f than in Fig. 6a-c.

The hardness values of bulk AlSi10Mg samples processed with a platform temperature of $200^{\circ} \mathrm{C}$ and LPBF printing time of roughly $10 \mathrm{~h}$ are summarized in Fig. 7. As shown in the figure, two specific heat treatments have been designed. The former is a prolonged isothermal heat treatment at $200^{\circ} \mathrm{C}$ to extend the heated platform effect for longer printing times (up to $100 \mathrm{~h}$ ). The latter is conventional T6like heat treatment. Before the heat treatments, asbuilt samples show a hardness value of $100.5 \pm 3$ $\mathrm{HV}$ that is significantly far lower than those reported in the literature. ${ }^{23,24}$ Hence, it seems that
AlSi10Mg samples are already overaged after $10 \mathrm{~h}$ of printing time at $200^{\circ} \mathrm{C}$. After isothermal heat treatment at $200^{\circ} \mathrm{C}$ for $100 \mathrm{~h}$, a further decrease in hardness down to $91 \pm 0.62 \mathrm{HV}$ was revealed. However, by applying a T6-like heat treatment on both conditions, hardness values of 113.47 and 115.17 HV were obtained. These values correspond to a hardness increase of $12 \%$ and $26 \%$ for the asbuilt and isothermal heat-treated samples, respectively. Moreover, the hardness difference (roughly $10 \mathrm{HV}$ ) between the as-built and isothermal heattreated samples is offset by applying the T6 heat treatment. All the measured $\mathrm{HV}$ values lie in a narrow range between 111 and $118 \mathrm{HV}$, which is very close to the previously reported peak-aged hardness of the alloy after T6 heat treatment. ${ }^{25,26}$

The general microstructure of the as-built sample after isothermal heat treatment at $200^{\circ} \mathrm{C}$ for $100 \mathrm{~h}$ is shown in Fig. 8a. The typical 'fish scale' pattern consists of dual-half elliptical melt pools aligned along the laser scanning direction. Figure $8 \mathrm{~b}$ provides a representative high-magnification micrograph taken from the core region of a melt pool. Here, the microstructure mainly includes submicron-sized primary $\alpha$-Al cells surrounded by fibrous eutectic architecture. The observed morphology of $\alpha$ $\mathrm{Al}$ is, to some extent, columnar rather than cellular

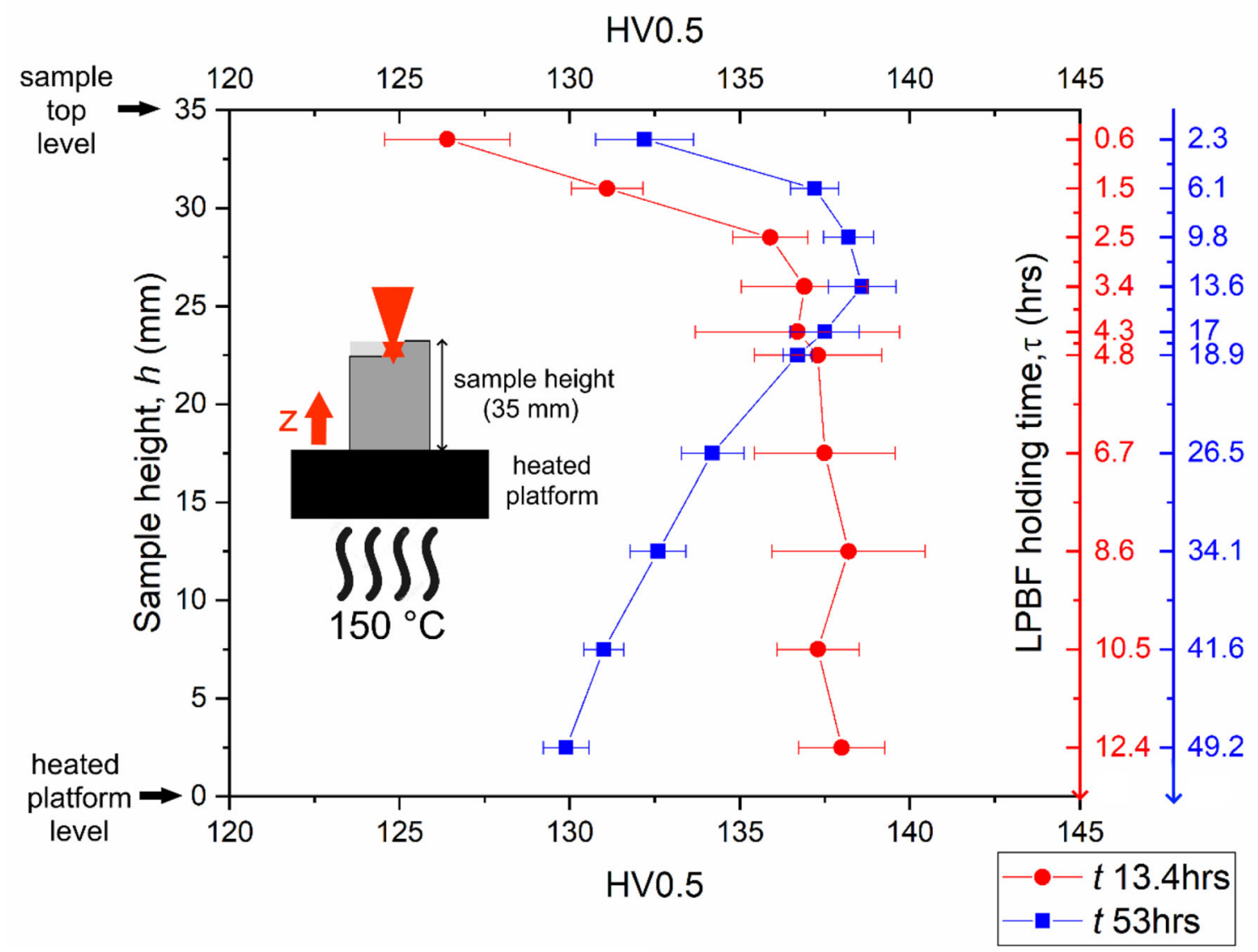

Fig. 5. Micro-hardness at different heights of AlSi10Mg samples built at different printing times (13.4 $\mathrm{h}$ and $53 \mathrm{~h})$ at a platform temperature of $150^{\circ} \mathrm{C}$. The hardness values are plotted as a function of the specimen heights and the corresponding LPBF holding times. 

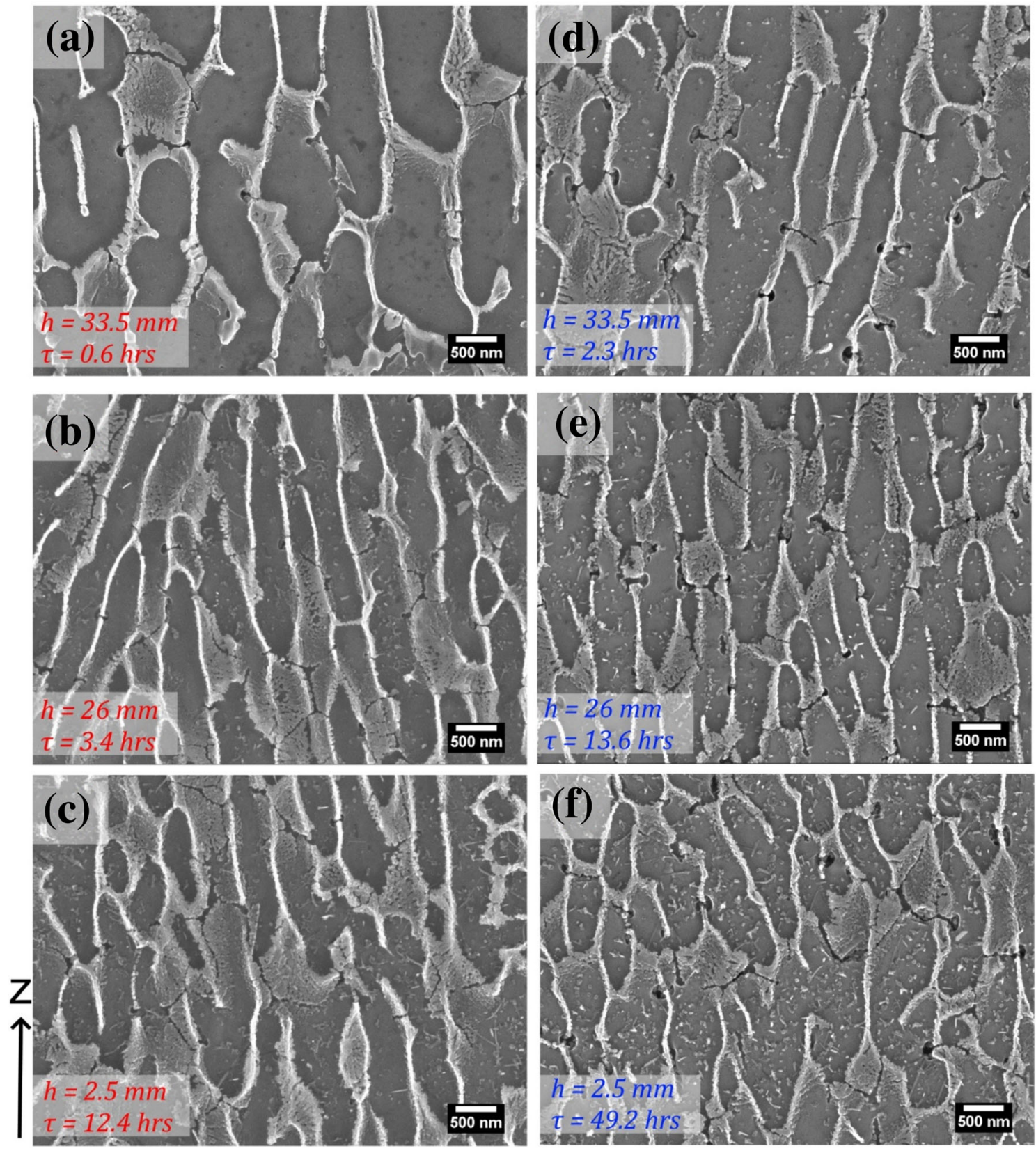

Fig. 6. Microstructure evolution along building direction of samples built upon $(\mathrm{a}-\mathrm{c}) 13.4 \mathrm{~h}$ and $(\mathrm{d}-\mathrm{f}) 53 \mathrm{~h}$ of printing time above a platform heated at $150^{\circ} \mathrm{C}$. Micrographs in $(\mathrm{a}-\mathrm{c})$ and $(\mathrm{d}-\mathrm{f})$ are arranged according to decreasing sample height $(\mathrm{h})$ or increasing LPBF holding time $(\tau)$ (from top to bottom) SEM investigations were performed in a melt pool core next to the corresponding HV measurements reported in Fig. 5 .

because of the directional heat flux toward the building substrate. However, some rounded cells with a size of $0.41 \pm 0.03 \mu \mathrm{m}$ have also been identified. Moreover, a remarkable amount of tiny intracolumnar precipitates exist in the $\alpha$-Al matrix. They most likely originate from the diffusion and precipitation of $\mathrm{Si}$ atoms.

Figure $8 \mathrm{c}$ and $\mathrm{d}$ provide representative micrographs of AlSi10Mg samples after isothermal heat treatment and subsequent T6-like heat treatment. In Fig. 8c, the 'fish-scale' microstructure almost disappears because of the Al-Si eutectic and $\mathrm{Si}$ particles coarsening during the heat treatment. Note that few tracks of melt pool boundaries have been observed, as indicated by arrows in Fig. 8c. Inspection of the high-magnification image in Fig. 8d reveals the Si particles (see supplementary Fig. S-2) with a size range between 0.3 and $4 \mu \mathrm{m}$. Apart from these Si particles, elongated precipitates with a plate-like shape have also been observed. They have a maximum length of $12 \mu \mathrm{m}$ and averaged thickness of $0.41 \pm 0.12 \mu \mathrm{m}$. These 


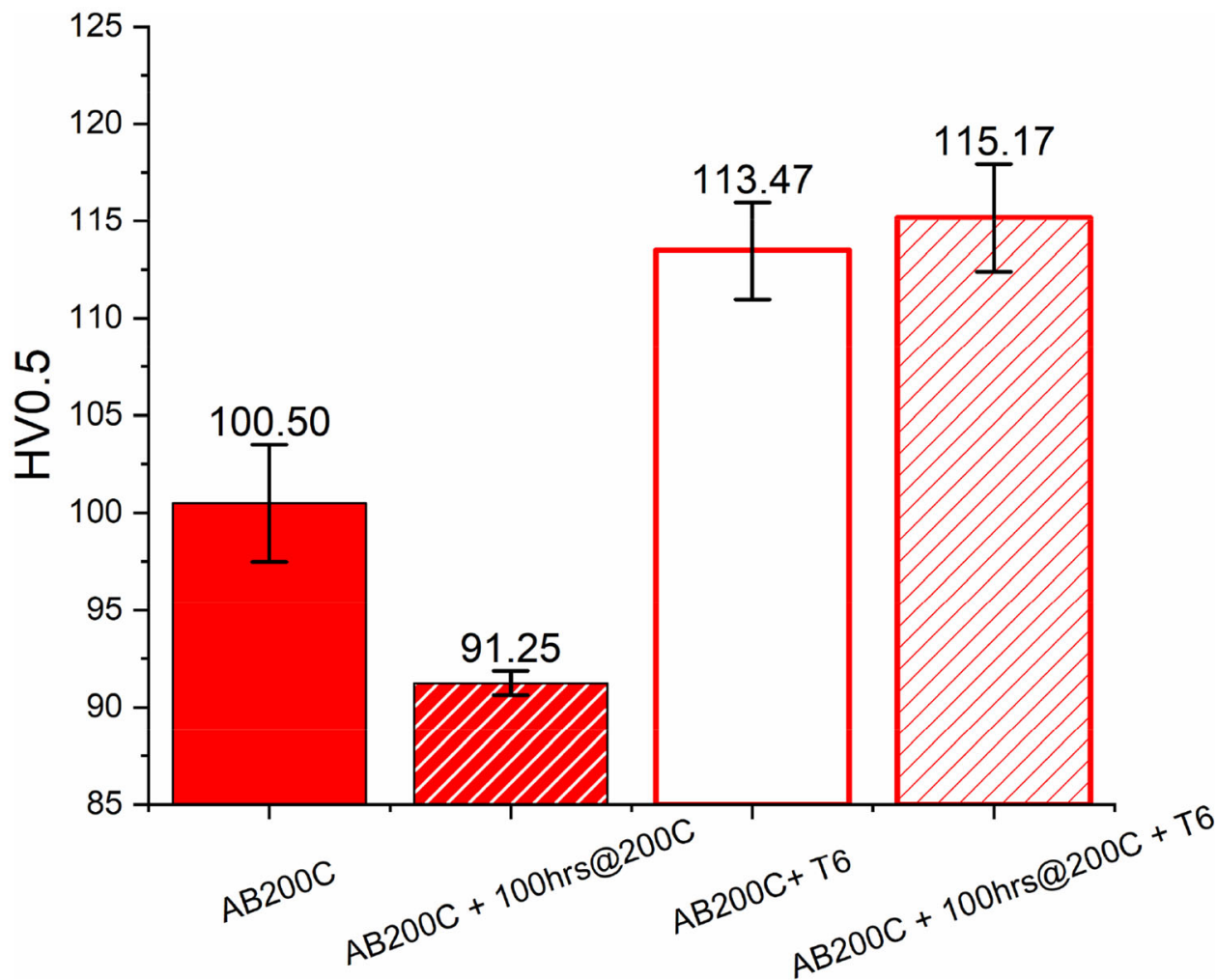

Fig. 7. Micro-hardness of the as-built and post-process heat-treated samples processed with a platform heating temperature of $200^{\circ} \mathrm{C}$.

precipitates are the phase enriched in Fe, as evidenced by the EDS mapping shown in Fig. S-2. This type of precipitate was also reported previously in the SLM-produced A357 and AlSi10Mg after heat treatments. ${ }^{9,20}$

\section{DISCUSSION}

The production of massive AlSi10Mg parts involves essential challenges to deal with at the design stage due to the internal residual stresses formed from rapid cooling. As a result, preventing cracks and distortions has been the first key issue to be addressed. In this work, a building platform heating strategy was adopted throughout the printing process to alleviate internal residual stresses. Four heating temperatures were selected to find the proper temperature level to avoid cracks and distortions. The results revealed that these defects can be successfully prevented in cantilever samples produced at a platform temperature of $150^{\circ} \mathrm{C}$ and above. This can be explained by the fact that the solidification shrinkage of built parts can be reduced by the small temperature difference between the heated building platform and the AlSi10Mg solidus $\left(557^{\circ} \mathrm{C}\right) .^{4,27}$ When the first powder layer of the cantilever arms is melted during LPBF, a natural thermal expansion of the melted alloy followed by a compression upon cooling is expected to occur. However, the shrinkage of the solidified layer is hindered by the robust support structure underneath, creating high tensile residual stresses in the opposite direction, which in turn will lead to fins bending and then crack initiation. ${ }^{15}$ By increasing the platform heating temperatures, the current results have shown that cantilever deflections decrease at $150^{\circ} \mathrm{C}$ and become negligible at $200^{\circ} \mathrm{C}$. The findings are in good agreement with earlier research by Buchbinder et al. ${ }^{15}$

The Al-Si-Mg alloy is one of the main classes of heat-treatable alloys that exhibit apparent precipitation hardening response during aging. ${ }^{28}$ Hence, it is technologically crucial to identify the in situ aging effect for long building time upon the heated platform because such an effect will eventually influence the mechanical properties of the parts. In this work, micro-hardness evaluation of parallelepiped samples processed on a platform heated up at $150^{\circ} \mathrm{C}$ with different printing times has shown distinct aging behavior (Fig. 5). For the printing time of $13.4 \mathrm{~h}$, the measured hardness along the building direction was consistent with the results of a heat treatable SLM-produced A357 alloy reported by Casati et al. ${ }^{29}$ It has to be noted that, in their work, a direct aging study was performed separately on bulk samples after the LPBF process, showing a peak-aged hardness of $137 \mathrm{HV}$ for an aging time of $4 \mathrm{~h}$ at $160^{\circ} \mathrm{C}$. In comparison, the same hardness value was achieved in the current work after around $3.4 \mathrm{~h}$ of holding time at a platform temperature of $150^{\circ} \mathrm{C}$. As for the printing time of $53 \mathrm{~h}$, our results 

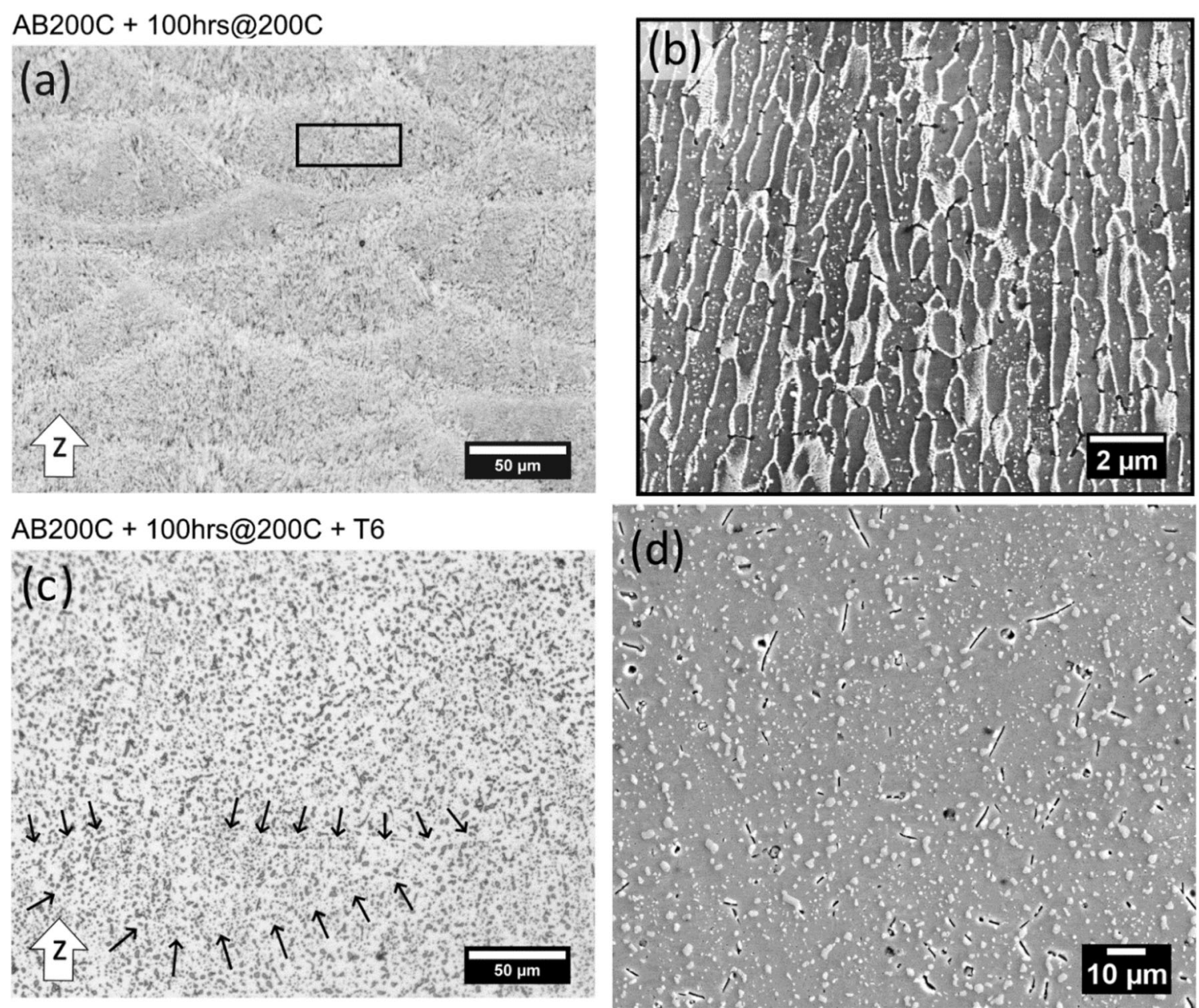

Fig. 8. (a) Optical and (b) SEM micrographs of AISi10Mg sample after isothermal heat treatment at $200^{\circ} \mathrm{C}$ for $100 \mathrm{~h}$; (c) optical and (d) SEM micrographs of AISi10Mg alloy after isothermal heat treatment $\left(100 \mathrm{~h}\right.$ at $\left.200^{\circ} \mathrm{C}\right)$ plus T6-like heat treatment.

indicate the occurrence of over-aging throughout the sample. A similar aging response has been reported in previous work ${ }^{13}$ for a SLM-produced AlSi $10 \mathrm{Mg}$ alloy directly aged in a furnace at $160^{\circ} \mathrm{C}$ after printing on a non-heated platform. Also, the over-aging can be evidenced by the microstructure examination shown in Fig. $6 \mathrm{f}$. The evolution of microstructure immediately after melting involves the consolidation of the Si-supersaturated $\alpha-\mathrm{Al}$ liquid primarily into a cellular/columnar structure with an extended $\mathrm{Si}$ solute content. Later, the residual $\mathrm{Si}$ segregates at the cell boundaries, generating a fibrous eutectic texture. ${ }^{21,30}$ Due to the intimate contact with the heated platform, it was also highly probable that the high holding time experienced at $150^{\circ} \mathrm{C}$ promotes the diffusion of the $\mathrm{Si}$ atoms in the $\alpha$-Al supersaturated solid solution. In this way, massive precipitation of fine intracolumnar particles takes place accordingly, disrupting the eutectic network and affecting the hardness. These fine particles were previously identified as pure $\mathrm{Si}$ particles in a SLMproduced A357 alloy with direct aging at $160^{\circ} \mathrm{C}$ for $8 \mathrm{~h}^{9}$
According to the current results, we advise adopting a platform temperature of $150^{\circ} \mathrm{C}$ and holding times lower than $13 \mathrm{~h}$ to prevent over-aging. Such a strategy will lead to more uniform hardness in the as-built sample and, simultaneously, partially release internal residual stresses without the need for post-process heat treatments. On the other hand, for large parts with critical shapes that require more than $13 \mathrm{~h}$ of LPBF printing, a platform temperature of $200^{\circ} \mathrm{C}$ can be used to reduce internal stresses. However, a relatively low hardness value will be obtained, which is coupled with a microstructure severely enriched by sub-micron particles (Fig. 8b). This weakening was ascribed to the former Si diffusion from the $\alpha$-Al supersaturated solid solution that contributed to the formation of fine precipitates within $\mathrm{Si}$ cells and the concurrent low-temperature stress relieving, as recently reported in Refs. ${ }^{31,32}$ by Fiocchi et al. In this case, a remedy to the over-aging phenomenon can be applied by using post-process heat treatment. $26,33,34$ When the T6 heat treatment was applied, the current work witnessed a remarkable increase of hardness up to $115 \mathrm{HV}$, which is comparable to that 
of die-cast A360-T6 counterparts. ${ }^{25,35}$ Such strengthening is mainly due to the dispersion of $\mathrm{Si}$ spheroids, which can act as obstacles to dislocation motion. ${ }^{34,36}$ It is interesting to note that most published works have reported a slight impoverishment of strength in the heat-treated condition, $9,25,34,36$ which is different from the current results. The T6 heat treatment can also help to enhance fatigue properties of printed components, as documented by others. ${ }^{8,37}$ Based on the above discussion, when LPBF processes large parts of aluminum, a new production strategy, including platform heating of $200^{\circ} \mathrm{C}$ and T6-like heat treatment, can be applied to achieve in situ stress relief and high hardness.

\section{CONCLUSION}

In summary, the present work set up a production strategy for LPBF to produce large parts of AlSi10Mg by considering two main aspects: the inevitable presence of residual stress that can cause job failure during a long printing time, and the in situ aging of the processed alloy. By using a platform heating strategy, we first defined the platform temperatures for preventing cracks and support distortions. Then, these temperatures were adopted in the second stage for the in situ aging investigations, leading to the following findings:

1. Building platform temperatures, set at $150^{\circ} \mathrm{C}$ and above, can effectively remove internal residual stresses and largely reduce part distortions for long-time LPBF jobs.

2. The in situ aging response occurs at a platform heating temperature of $150^{\circ} \mathrm{C}$. The hardness reaches a peak with a holding time between $3.4 \mathrm{~h}$ and $13.4 \mathrm{~h}$. Over-aging starts to appear when the holding time is longer than $13.4 \mathrm{~h}$.

3. As-built and isothermal heat-treated samples processed at $200^{\circ} \mathrm{C}$ clearly show the over-aging response, reaching the lowest $\mathrm{HV}$ value after $100 \mathrm{~h}$ at $200^{\circ} \mathrm{C}$.

4. A T6-like heat treatment was found to be able to recover the loss of hardness induced by overaging at $200^{\circ} \mathrm{C}$, increasing the $\mathrm{HV}$ value by $26 \%$ in the best scenario.

In conclusion, for producing large parts with critical shapes, a platform heating temperature of $200^{\circ} \mathrm{C}$ can be used to minimize distortions and bending of parts during LPBF. Nevertheless, the high printing time inevitably induces over-aging weakening, and the T6-like heat treatment can be applied to achieve mechanical properties comparable to the die-cast counterparts. On the other hand, for smaller parts requiring a printing time shorter than $13 \mathrm{~h}$, a heated platform set at the aging temperature for $\mathrm{Al}$ alloys can be used to obtain directly peak-aged parts made of AlSi10Mg without the need for any post-process heat treatments.

\section{ACKNOWLEDGEMENTS}

The authors acknowledge financial support from the Australian Research Council, and access to the facilities in the Monash Centre for Electron Microscopy (MCEM) and Monash Centre for Nanofabrication (MCN). The authors want to thank Dr. Xiya Fang in the MCEM and Dr. Derui Jiang in the Monash Centre for Additive Manufacturing (MCAM) for their support with the experiments.

\section{CONFLICT OF INTEREST}

The authors declare that they have no conflict of interest.

\section{ELECTRONIC SUPPLEMENTARY MATERIAL}

The online version of this article (https://doi.org/ 10.1007/s11837-020-04523-8) contains supplementary material, which is available to authorized users.

\section{REFERENCES}

1. D. Herzog, V. Seyda, E. Wycisk, and C. Emmelmann, Acta Mater. 117, 371 (2016).

2. N. Li, S. Huang, G. Zhang, R. Qin, W. Liu, H. Xiong, G. Shi, and J. Blackburn, J. Mater. Sci. Technol. 35, 242 (2018).

3. F. Calignano, Mater. Des. 64, 203 (2014).

4. P. Mercelis and J.P. Kruth, Rapid Prototyp. J. 12, 254 (2006).

5. M.F. Zaeh and G. Branner, Prod. Eng. 4, 35 (2010).

6. T. Kimura and T. Nakamoto, Mater. Des. 89, 1294 (2016).

7. H. Rao, S. Giet, K. Yang, X. Wu, and C.H.J. Davies, Mater. Des. 109, 334 (2016).

8. E. Brandl, U. Heckenberger, V. Holzinger, and D. Buchbinder, Mater. Des. 34, 159 (2012).

9. K.V. Yang, P. Rometsch, C.H.J. Davies, A. Huang, and X. Wu, Mater. Des. 154, 275 (2018).

10. U. Tradowsky, J. White, R.M. Ward, N. Read, W. Reimers, and M.M. Attallah, Mater. Des. 105, 212 (2016).

11. H.A. Ferguson, Heat Treat. Alum. Alloys 4, 841 (1991).

12. A. Aversa, M. Lorusso, F. Trevisan, E. Ambrosio, F. Calignano, D. Manfredi, S. Biamino, P. Fino, M. Lombardi, and M. Pavese, Metals (Basel) 7, 68 (2017).

13. M. Coduri, M. Hamidi Nasab, M. Vedani, R. Casati, and V. Tirelli, Metals (Basel) 8, 954 (2018).

14. J.H. Rao, Y. Zhang, K. Zhang, X. Wu, and A. Huang, Mater. Des. 182, 108005 (2019).

15. D. Buchbinder, W. Meiners, N. Pirch, K. Wissenbach, and J. Schrage, J. Laser Appl. 26, 012004 (2014).

16. F. Bosio, A. Aversa, M. Lorusso, S. Marola, D. Gianoglio, L. Battezzati, P. Fino, D. Manfredi, and M. Lombardi, Mater. Des. 181, 107949 (2019).

17. A.H. Maamoun, Y.F. Xue, M.A. Elbestawi, and S.C. Veldhuis, Materials (Basel) 12, 12 (2018).

18. A.H. Maamoun, Y.F. Xue, M.A. Elbestawi, and S.C. Veldhuis, Materials (Basel) 11, 2343 (2018).

19. T. DebRoy, H.L. Wei, J.S. Zuback, T. Mukherjee, J.W. Elmer, J.O. Milewski, A.M. Beese, A. Wilson-Heid, A. De, and W. Zhang, Prog. Mater. Sci. 92, 112 (2018).

20. L. Zhou, A. Mehta, E. Schulz, B. McWilliams, K. Cho, and Y. Sohn, Mater. Charact. 143, 5 (2018). 
21. L. Thijs, K. Kempen, J.P. Kruth, and J. Van Humbeeck, Acta Mater. 61, 1809 (2013).

22. S. Marola, D. Manfredi, G. Fiore, M.G. Poletti, M. Lombardi, P. Fino, and L. Battezzati, J. Alloys Compd. 742, 271 (2018).

23. N.T. Aboulkhair, M. Simonelli, L. Parry, I. Ashcroft, C. Tuck, and R. Hague, Prog. Mater Sci. 106, 100578 (2019).

24. S. Marola, D. Gianoglio, F. Bosio, A. Aversa, M. Lorusso, D. Manfredi, M. Lombardi, and L. Battezzati, J. Alloys Compd. 821,153538 (2020).

25. L. Girelli, M. Tocci, M. Gelfi, and A. Pola, Mater. Sci. Eng. A 739, 317 (2019).

26. A.H. Maamoun, M. Elbestawi, G.K. Dosbaeva, and S.C. Veldhuis, Addit. Manuf. 21, 234 (2018).

27. J.P. Kruth, J. Deckers, E. Yasa, and R. Wauthlé, Proc. Inst. Mech. Eng. Part B J. Eng. Manuf. 226, 980 (2012).

28. C.H.J. Davies, K. Zhang, J.H. Rao, X. Wu, A. Huang, and Y. Zhang, Scr. Mater. 160, 66 (2018).

29. R. Casati and M. Vedani, Adv. Eng. Mater. 1800406, 1800406 (2018).
30. K.G. Prashanth, S. Scudino, H.J. Klauss, K.B. Surreddi, L. Löber, Z. Wang, A.K. Chaubey, U. Kühn, and J. Eckert, Mater. Sci. Eng. A 590, 153 (2014).

31. J. Fiocchi, A. Tuissi, P. Bassani, and C.A. Biffi, J. Alloys Compd. 695, 3402 (2017).

32. J. Fiocchi and C.A. Biffi, JOM 72, 1118 (2020).

33. S. Li, J. Liu, Y. Shi, Q. Wei, W. Li, A. Zhang, C. Yan, and Y. Zhou, Mater. Sci. Eng. A 663, 116 (2016).

34. N.T. Aboulkhair, I. Maskery, C. Tuck, I. Ashcroft, and N.M. Everitt, Mater. Sci. Eng. A 667, 139 (2016).

35. L. Roger, CSIRO Light Met. Flagsh. (2008).

36. N.T. Aboulkhair, C. Tuck, I.A.N. Ashcroft, I.A.N. Maskery, and N.M. Everitt, Metall. Mater. Trans. A 46, 3337 (2015).

37. N.T. Aboulkhair, I. Maskery, C. Tuck, I. Ashcroft, and N.M. Everitt, JMADE 104, 174 (2016).

Publisher's Note Springer Nature remains neutral with regard to jurisdictional claims in published maps and institutional affiliations. 